\title{
Resveratrol suppresses body mass gain in a seasonal non-human primate model of obesity
}

\author{
Alexandre Dal-Pan1, Stéphane Blanc² and Fabienne Aujard*1
}

\begin{abstract}
Background: Resveratrol, a natural polyphenolic compound, was shown to protect rodents against high-fat-diet induced diabesity by boosting energy metabolism. To the best of our knowledge, no data is yet available on the effects of resveratrol in non-human primates. Six non-human heterotherm primates (grey mouse lemurs, Microcebus murinus) were studied during four weeks of dietary supplementation with resveratrol ( $200 \mathrm{mg} / \mathrm{kg} /$ day) during their winter bodymass gain period. Body mass, spontaneous energy intake, resting metabolic rate, spontaneous locomotor activity and daily variations in body temperature were measured. In addition, the plasma levels of several gut hormones involved in satiety control were evaluated.

Results: Resveratrol reduced the seasonal body-mass gain by concomitantly decreasing energy intake by $13 \%$ and increasing resting metabolic rate by $29 \%$. Resveratrol supplementation inhibited the depth of daily torpor, an important energy-saving process in this primate. The daily amount of locomotor activity remained unchanged. Except for an increase in the glucose-dependent insulinotropic polypeptide, a gut hormone known to promote mobilization of fat stores, no major change in satiety hormone plasma levels was observed under resveratrol supplementation.
\end{abstract}

Conclusions: These results suggest that in a non-human primate, resveratrol reduces body-mass gain by increasing satiety and resting metabolic rate, and by inhibiting torpor expression. The measured anorectic gut hormones did not seem to play a major role in these observations.

\section{Background}

Obesity stems from a prolonged imbalance between the level of energy intake and energy expenditure, with the resultant surplus being stored as lipids predominantly in adipose tissue, but also in muscle and liver tissue, triggering features of the metabolic syndrome. Understanding the factors which regulate both energy intake and expenditure, such as environmental/lifestyle manipulations or pharmaceuticals, is an important step towards developing obesity treatments.

The physiological benefits of resveratrol (3,4',5-trihydroxystilbene or RSV), a natural polyphenol, are currently under intensive investigation. Resveratrol is produced by plants in response to infection by the pathogen Botrytis cinerea [1]. It is also induced in response to a variety of stress conditions (climate, exposure to ozone, sunlight and heavy metals) [2]. Presently, it has been

* Correspondence: fabienne.aujard@wanadoo.fr

${ }^{1}$ Mécanismes Adaptatifs et Evolution, UMR 7179 Centre National de la Recherche Scientifique, Muséum National d'Histoire Naturelle, Paris, France Full list of author information is available at the end of the article detected in more than 70 plant species, including grapes, peanuts, berries and pines [2]. Resveratrol is able to activate nicotinamide adenosine dinucleotide-dependent deacetylase SIRT1 (Silent mating type Information Regulation 2 homologue Type 1), one of the seven mammalian sirtuins $[3,4]$ involved in glucose homeostasis and lipid metabolism. This activation of SIRT1 by RSV seems to prevent obesity by inducing oxidative mitochondrial metabolism [5] and reduced insulin resistance [6] in mice on a high-caloric diet. In the same way, RSV minimizes hyperglycaemia in diet-induced obese and diabetic mice [7], and dyslipidemia in the experimental model of obese Zucker rats. These rodent models are widely used as animal models of obesity and type 2 diabetes which present many features of the human metabolic syndrome [8]. The validity of information obtained in primates, particularly in humans, is still under debate because the experimental protocols used in the preliminary studies were quite different from each other [9]. Moreover, recent works have demonstrated that RSV supplementation mimics caloric 
restriction in mice [10], suggesting that RSV could be a good candidate for the development of obesity therapies.

However, most RSV studies focused on changes in energy expenditure and its related cellular mechanisms $[11,12]$ and were mainly obtained from genetically modified mouse models of obesity [13] or in the context of a high-fat diet $[14,11]$. The effects of RSV on spontaneous food intake and its regulation are still unclear and still unknown in primates.

The aim of the present study was thus to determine the effects of a four-week RSV supplementation on energy metabolism and spontaneous food intake in a nonhuman primate, the grey mouse lemur (Microcebus muri$n u s$ ), which demonstrates seasonal spontaneous obesity. Grey mouse lemurs present high photoperiod-dependent variations in body mass associated with energy saving mechanisms, in particular a phase of heterothermia during their daily resting period. When exposed to a short photoperiod, mouse lemurs display a fast and linear body-mass gain (about 6-8 g/week) associated with a high caloric intake. In just a few weeks, a near $100 \%$ increase in body mass is observed due to high levels of fat storage, while the duration and depth of daily hypothermia bouts increase $[15,16]$.

The effect of RSV supplementation on body mass, resting metabolic rate (RMR), daily body temperature $(\mathrm{Tb})$ variations and spontaneous food intake in the grey mouse lemur was explored to investigate of the hypothesis that RSV supplementation will affect the time courses of prewintering fattening mechanisms in this primate. Because previous studies on mouse lemurs have suggested that several gut hormones may be related to the pre-wintering fattening phase and to the daily heterothermia expression [17], we also tested the effects of RSV supplementation on several gut-derived peptide hormones that are involved in numerous aspects of fuel homeostasis [18]. We measured glucagon-like peptide 1 (GLP-1), pancreatic polypeptide (PP), peptide YY (PYY) and glucosedependent insulinotropic polypeptide (GIP). Glucagonlike peptide 1 and PYY were shown to decrease energy expenditure and food intake [19]. Conversely, PP and GIP induced an increase in energy expenditure, motor activity and mobilization of fat stores [20]. Consequently, possible relationships between the key parameters involved in energy balance regulation and gut hormones in grey mouse lemurs were also investigated.

\section{Results}

During the control week prior to RSV supplementation, the studied animals presented an average body-mass gain of $6.2 \pm 1.3 \%(1.2 \mathrm{~g} / \mathrm{d})$ from their initial mass $(133 \pm 4 \mathrm{~g})$. At the end of the four weeks of RSV supplementation, the body-mass gain was gradually suppressed to $1.0 \pm 0.3 \%$ $(0.5 \mathrm{~g} / \mathrm{d}, \mathrm{F}=14.0, \mathrm{df}=4, \mathrm{p}=0.007$, Figure $1 \mathrm{~A})$. A $13 \%$ decrease in spontaneous food intake was noted from the third week of RSV treatment (from $121.4 \mathrm{~kJ} / \mathrm{d}$ to $104.7 \mathrm{~kJ} /$ $\mathrm{d}, \mathrm{F}=10.4, \mathrm{df}=4, \mathrm{p}=0.035$, Figure $1 \mathrm{~B})$. The $\mathrm{RMR}$ increased by $29 \%$ after four weeks of RSV treatment compared to the control period $(\mathrm{F}=12.7, \mathrm{df}=4, \mathrm{p}=0.013$, Figure 1C). Total daily locomotor activity (LA) was not modified by RSV treatment (164 \pm 23 a.u. in the control week vs. $168 \pm 12$ a.u. in the fourth week of treatment, F = $0.4, \mathrm{df}=4, \mathrm{p}=0.980$, Figure 1D). A representative profile of the weekly average of variations in $\mathrm{Tb}$ of one mouse lemur is represented in Figure 2A. The mouse lemurs exhibited a significant increase in their mean $\mathrm{Tb}$ during the diurnal phase ( $\mathrm{Tb}$ day) with a gain of $1.0 \pm 0.3^{\circ} \mathrm{C}$ between the control and the fourth week of treatment $\left(34.7 \pm 0.5^{\circ} \mathrm{C}\right.$ vs. $\left.35.6 \pm 0.1^{\circ} \mathrm{C}, \mathrm{F}=14.3, \mathrm{df}=4, \mathrm{p}=0.006\right)$. The minimal $\mathrm{Tb}$ value ( $\mathrm{Tb} \mathrm{min}$ ) of the animals increased by $1.5 \pm 0.6^{\circ} \mathrm{C}$ between the control and the fourth week of treatment $\left(32.4 \pm 0.8^{\circ} \mathrm{C}\right.$ vs. $33.9 \pm 0.4^{\circ} \mathrm{C}, \mathrm{F}=11.1, \mathrm{df}=4, \mathrm{p}$ $=0.026$ ). The amplitude of the phase of daily hypothermia was greatly reduced in response to RSV supplementation. On the other hand, no significant change in the mean $\mathrm{Tb}$ during the active nocturnal phase (Tb night) was found in response to RSV supplementation (36.4 \pm $0.1^{\circ} \mathrm{C}$ vs. $36.6 \pm 0.1^{\circ} \mathrm{C}, \mathrm{F}=3.3, \mathrm{df}=4, \mathrm{p}=0.504$ ) (Figure 2B).

No significant time-course change was reported for GLP-1, PP and PYY levels. Only the GIP level was significantly increased by RSV after four weeks of supplementation $(104 \pm 14 \mathrm{pg} / \mathrm{ml}$ in the control week vs. $175 \pm 39 \mathrm{pg} /$ $\mathrm{ml}$ in the fourth week, $\mathrm{F}=11.6, \mathrm{df}=4, \mathrm{p}=0.021$ ) (Table 1). Although trends are visible, the increased inter-individual variability observed during the treatment (from $21 \%$ to $61 \%, \mathrm{~F}=14.3, \mathrm{df}=4, \mathrm{p}=0.002)$ did not allow any significant conclusion to be reached. Lastly, no significant correlation could be found between the variations in gut hormones and the variations in body-mass gain, food intake or RMR (Table 2).

\section{Discussion}

The main findings of this study were: 1) a four-week resveratrol supplementation had significant effects on energy metabolism in the mouse lemur, characterized by a reduction in seasonal body-mass gain associated with an increase in resting metabolic rate and a decrease in food intake; 2) the response to resveratrol supplementation mainly involved a strong reduction of daily heterothermia expression with no change in the daily amount of locomotor activity; 3) despite the fact that glucosedependent insulinotropic polypeptide (GIP) values increased during resveratrol supplementation, no correlation was evidenced between the other tested gut hormones and changes in energy balance parameters.

Resveratrol supplementation was given to mouse lemurs at the very time of seasonal fattening induced by 
A

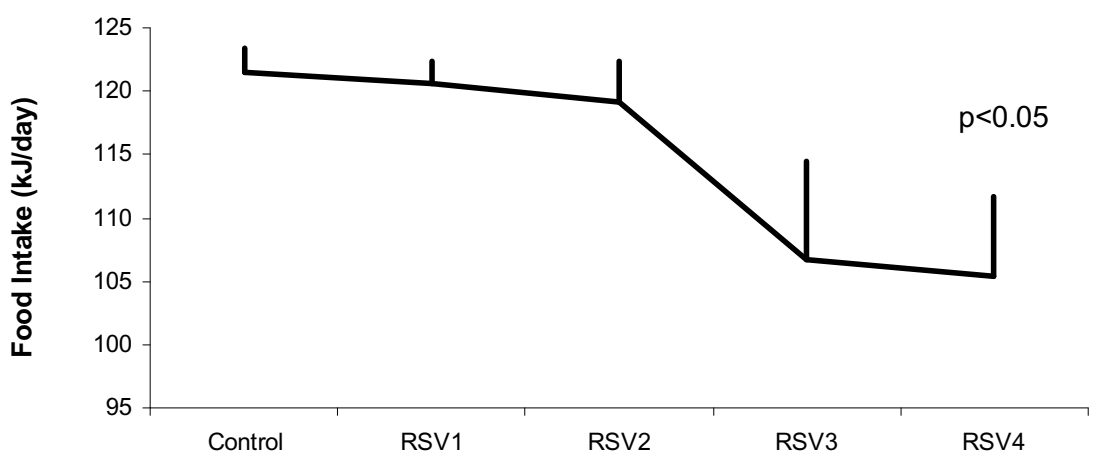

B

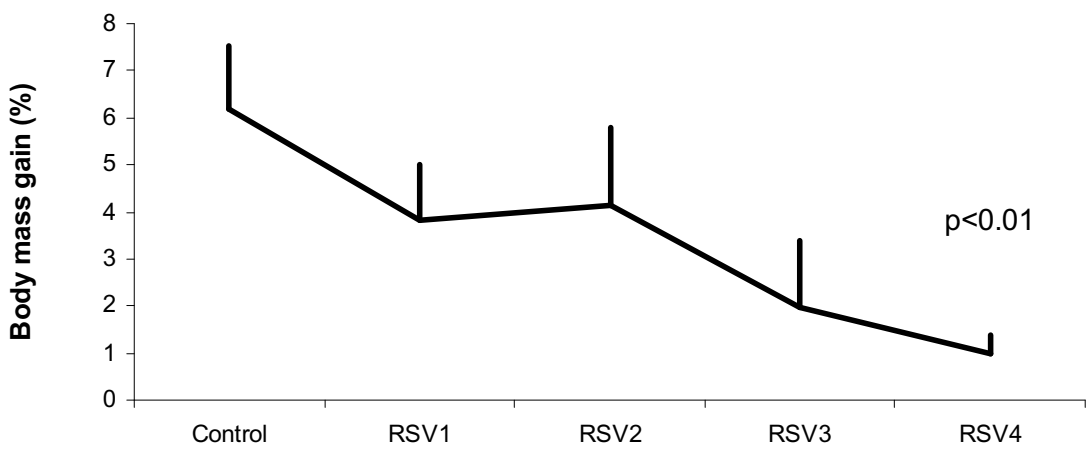

C

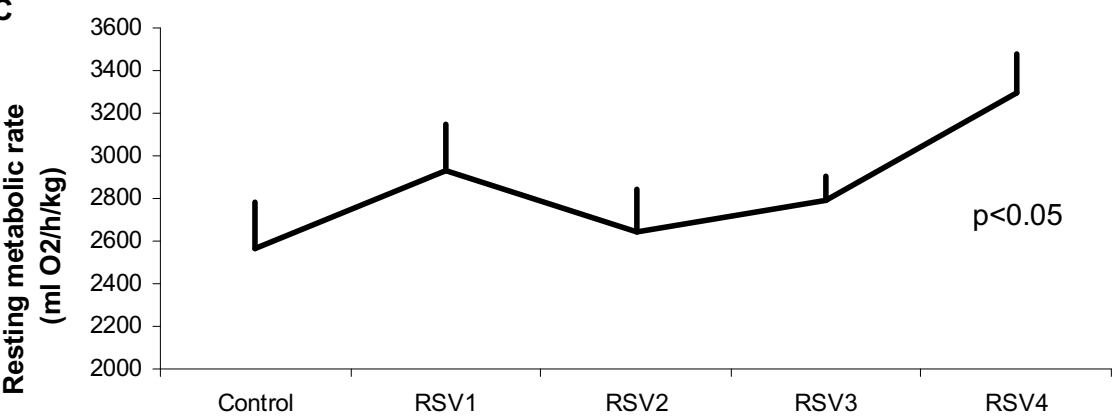

D

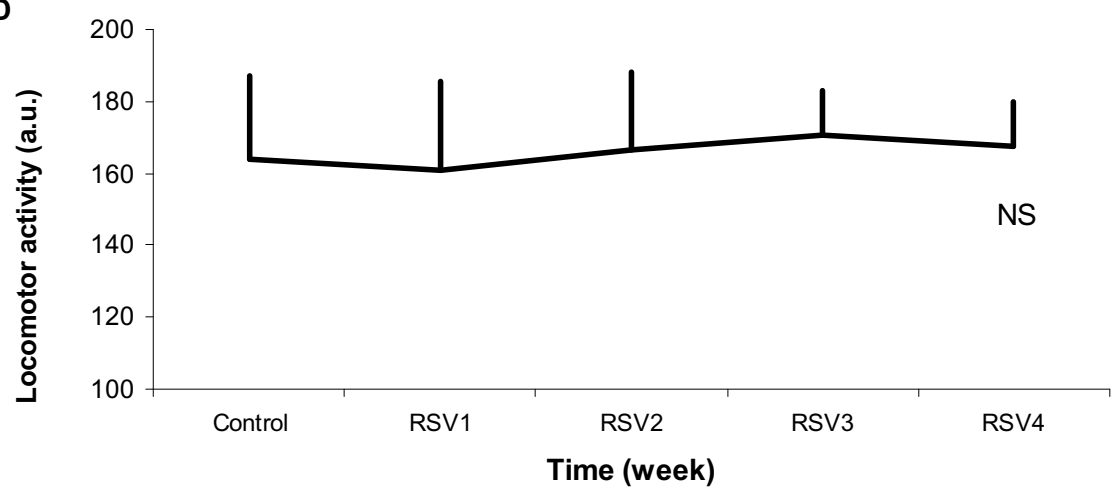

Figure 1 Resveratrol effects on parameters of energy balance. Six male mouse lemurs were observed during one week of ad libitum feeding (Control), followed by four weeks of RSV supplementation to the ad libitum feeding (RSV1, 2, 3 and 4). The curves represent the evolution with time of food intake (A), body-mass gain (B), resting metabolic rate (RMR) (C) and daily amount of locomotor activity (LA) (D). Values are given as mean \pm SEM. Resveratrol supplementation induced a significant decrease in food intake and body-mass gain associated with an increase in RMR. The amount of LA was not modified by the treatment. 


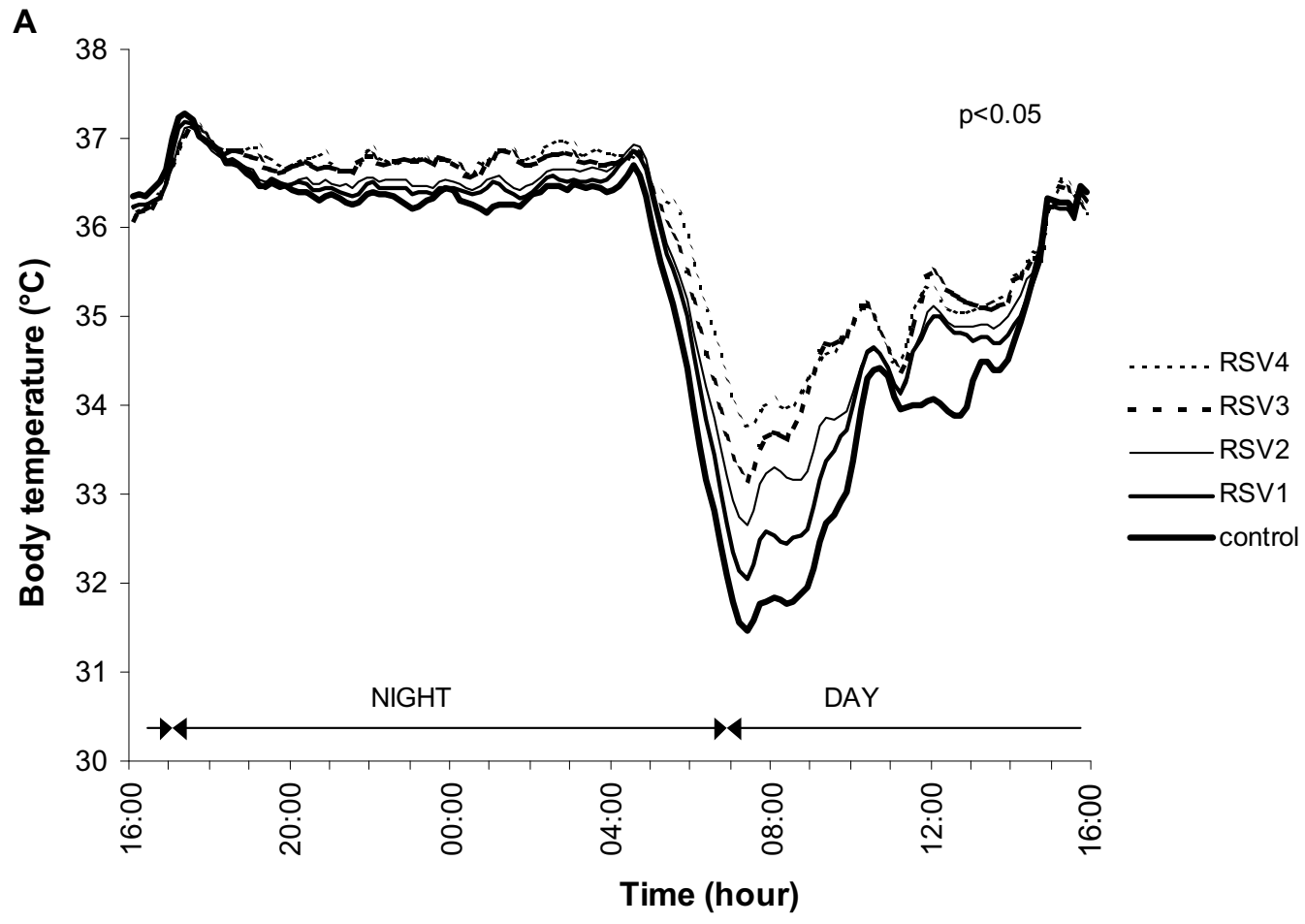

B

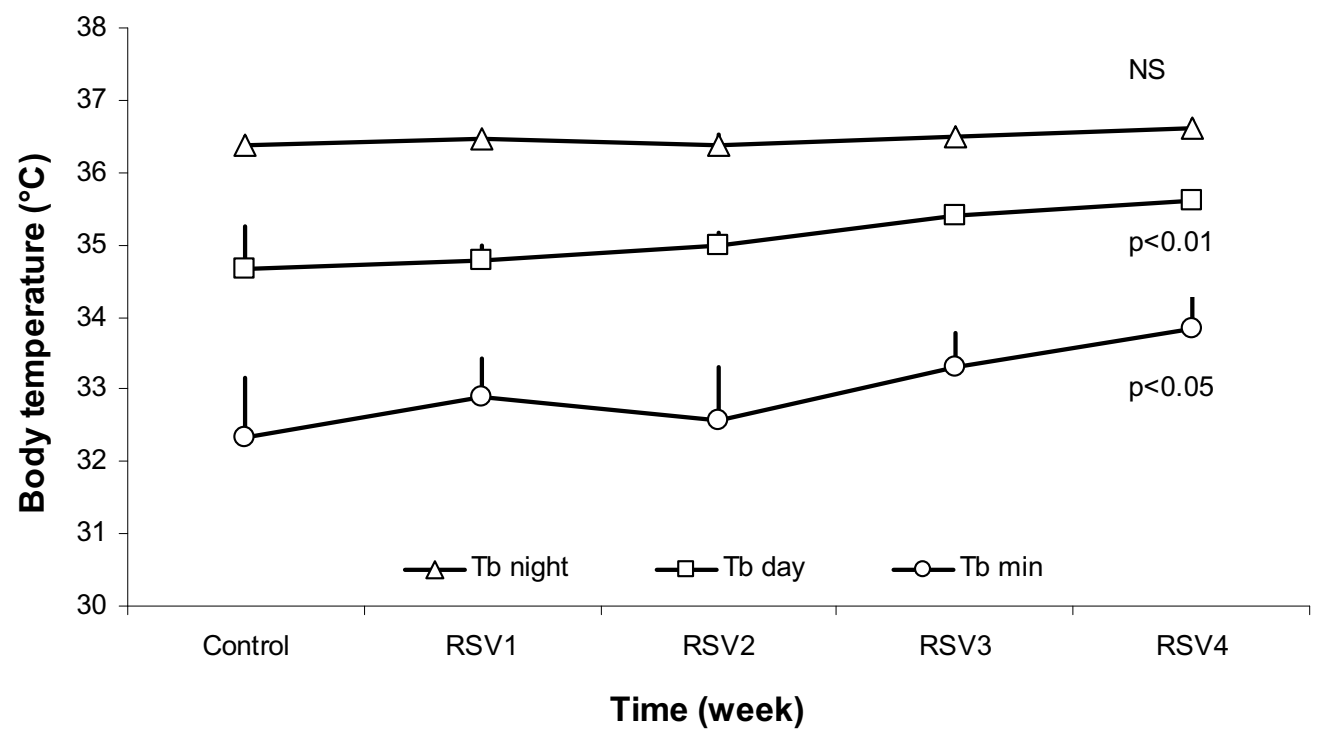

Figure 2 Resveratrol effects on body temperature of the animals. Six male mouse lemurs were observed during one week of ad libitum feeding (Control), followed by four weeks of RSV supplementation to the ad libitum feeding (RSV1, 2, 3 and 4). Panel (A) represents the average daily profiles of the Tb of one representative mouse lemur during the control week and during each week of RSV supplementation. Panel (B) illustrates the evolution of the diurnal (Tb day), nocturnal (Tb night) and minimal ( $\mathrm{Tb}$ min) body temperatures according to the duration of treatment. Values are given as mean \pm SEM. Resveratrol supplementation induced a clear reduction of the phase of daily torpor revealed by the significant increase in Tb day and Tb min values over the course of treatment. 
Table 1: Resveratrol effects on the levels of the different gut hormones tested during the four weeks of treatment.

\begin{tabular}{|c|c|c|c|c|c|c|}
\hline $\begin{array}{c}\text { Gut } \\
\text { hormones }\end{array}$ & Control & RSV1 & RSV2 & RSV3 & RSV4 & $\begin{array}{c}\text { Friedman } \\
\text { test }\end{array}$ \\
\hline GIP & $104 \pm 14$ & $123 \pm 25$ & $168 \pm 28$ & $187 \pm 33$ & $175 \pm 39$ & $\begin{array}{c}F=11.6, d f=4, \\
p=0.021\end{array}$ \\
\hline GLP-1 & $673 \pm 25$ & $705 \pm 34$ & $899 \pm 139$ & $1088 \pm 293$ & $1080 \pm 295$ & $\begin{array}{c}F=0.7, d f=4 \\
p=0.949\end{array}$ \\
\hline PP & $205 \pm 17$ & $206 \pm 22$ & $193 \pm 18$ & $148 \pm 36$ & $140 \pm 33$ & $\begin{array}{c}F=4.2, d f=4 \\
p=0.385\end{array}$ \\
\hline PYY & $298 \pm 11$ & $299 \pm 16$ & $329 \pm 23$ & $293 \pm 47$ & $261 \pm 57$ & $\begin{array}{c}F=1.8, d f=4 \\
p=0.779\end{array}$ \\
\hline
\end{tabular}

The gut hormone levels investigated were glucose-dependent insulinotropic polypeptide (GIP), glucagon-like peptide-1 (GLP-1), pancreatic polypeptide (PP) and peptide YY (PYY). RSV1, 2, 3 and 4 represent the four successive weeks of RSV treatment. Values are expressed in pg/ml and they are given as mean \pm SEM $(n=6)$

exposure to short day lengths. This period corresponds to an increase in both spontaneous food intake and frequency of deep torpor, leading to fast body mass gain through fat accumulation. Moreover, the resting metabolic rate and locomotor activity decrease, reinforcing the energy saving processes. Resveratrol supplementation appeared to limit all these energy saving mechanisms by acting more specifically on food intake and daily hypothermia bouts without change in locomotor activity.

The observed decrease in food intake in mouse lemurs cannot be related to the palatability of resveratrol as the mouse lemurs were not found to be averse to resveratrol prior to the experiment. It is more likely that an aversive palatability of resveratrol would have led to an immediate reduction in food intake which was not observed. However, the effects on food intake might have been related to the dose of resveratrol given. The dosage level administered in this study $(200 \mathrm{mg} / \mathrm{kg})$ was selected from studies in the literature on rodents, and was intermediate between the $40 \mathrm{mg} / \mathrm{kg}$ of Baur et al. [14] and the $400 \mathrm{mg} /$ $\mathrm{kg}$ of Lagouge et al. [12]. This dose was carefully mixed in the food and, since the animals tended to eat less than provided, the actual ingested dose of resveratrol was below $200 \mathrm{mg} / \mathrm{kg}$. The amount of resveratrol ingested by the animals was $96.1 \%$ in the first week and $84 \%$ in the fourth week (corresponding to an equivalent of $192 \mathrm{mg} /$ $\mathrm{kg} /$ day and $168 \mathrm{mg} / \mathrm{kg} /$ day, respectively). These amounts, based on the existing literature, appeared sufficiently high to be effective in mammals [21-23]. However, the observed satiety in resveratrol-supplemented mouse lemurs may be a sensibility response specific to this species or to primates.

Although the change in food intake could explain the reduction of seasonal body-mass gain, resveratrol supplementation significantly affected the body temperature patterns in the mouse lemur. Average values of energy savings by daily torpor in this species have been estimated to be about $40-70 \%$ as compared to the maintenance of normothermia [24,25]. Under resveratrol supplementation, the depth and the duration of daily torpor decreased and were associated with an increase in both body temperature and resting metabolic rate during the daily resting period. In contrast, body temperature values during the night active phase were not modified, and nor was locomotor activity. The decrease in energy savings during the daily diurnal rest would thus contribute to the reduction in body-mass gain under resveratrol supplementation.

Table 2: Correlations between the variations in gut hormone levels and the variations in energy parameters.

\begin{tabular}{|c|c|c|c|}
\hline Gut hormones & Body mass gain & Food intake & Resting metabolic rate \\
\hline GIP & $R=0.260, p=0.658$ & $R=0.260, p=0.658$ & $R=-0.200, p=0.714$ \\
\hline GLP-1 & $R=0.086, p=0.919$ & $R=0.543, p=0.297$ & $R=0.143, p=0.803$ \\
\hline $\mathbf{P P}$ & $R=-0.314, p=0.564$ & $R=0.657, p=0.175$ & $R=0.486, p=0.356$ \\
\hline PYY & $R=-0.029, p=1.000$ & $R=0.029, p=1.000$ & $R=0.086, p=0.919$ \\
\hline
\end{tabular}

Correlations were analysed between gut hormone levels (glucose-dependent insulinotropic polypeptide (GIP), glucagon-like peptide-1 (GLP-1), pancreatic polypeptide (PP) and peptide YY (PYY)) and variations in body mass gain, food intake and resting metabolic rate between the control week and the fourth week of RSV supplementation (all results are non significant) $(n=6)$. 
No such effect of resveratrol has been shown in mice, for which no change in food intake or body temperature was observed [11,13]. However, these data originate from experimentally-induced obesity and it is likely that the responses observed in mouse lemurs rely on specific lifehistory traits of this primate, which has developed high seasonal energy saving mechanisms and exhibits prewintering spontaneous obesity.

Resveratrol activates mammalian sirtuins, more specifically SIRT1, which is involved in glucose homeostasis and lipid metabolism. In mice exposed to a high-fat diet or in $\mathrm{ob} / \mathrm{ob}$ mice, resveratrol was shown to protect mice from diet-induced metabolic disorders $[12,13,26]$ by mimicking some effects of caloric restriction. Likewise, resveratrol and assimilated SIRT1 activators have been proposed as potential treatments for type 2 diabetes in mice models $[14,12,27,28]$. The effects of resveratrol have been suggested to depend on an increase in oxidative mitochondrial metabolism [14] and on enhanced fat oxidation [11], leading to an increase in energy expenditure. Interestingly, SRT1720, which activates SIRT1 by four fold in comparison to resveratrol, induces a significant decrease in fat mass without a change in food intake in mice [11]. In the mouse lemur, concomitantly to an increase in energy expenditure through decreasing hypothermia bouts and increasing metabolism, resveratrol might have a direct negative effect on fat storage.

Due to their involvement in satiety and satiation processes $[18,29,30]$, several gut hormones have been measured in resveratrol-supplemented mouse lemurs. No significant change was recorded after four weeks for the glucagon-like peptide 1 and the peptide YY, two gut hormones involved in the reduction of food intake and energy expenditure [31-34]. Conversely, the two other gut hormones are known to induce an increase in energy expenditure. The pancreatic polypeptide increases satiety, thus leading to a loss in body mass [20] and the glucose-dependent insulinotropic polypeptide (GIP) was shown to induce an increase in exploratory behaviour and performance in some motor function tests in a transgenic mouse that over-expressed GIP [35]. Only GIP significantly increased with resveratrol supplementation. Data emerging from studies in animal models and cultured human fat cells support a physiological role for GIP in fat cell metabolism, leading to the mobilization of fat stores $[17,36]$. Such effects might have contributed to the reduction in body-mass gain by limiting fat storage in supplemented mouse lemurs. The observed effect of resveratrol on food intake in the mouse lemur appears to be independent of changes in anorexic gut hormones, but the high observed inter-individual variability in our study does not allow definite conclusions to be reached. Moreover, because sampling was performed at a single point in fasted animals during the diurnal rest, changes may have been missed.

Resveratrol has been studied as a potential mimetic of caloric restriction [4]. However, caloric restriction decreases the metabolic rate [37], whereas resveratrol had the opposite effect [12]. From previous studies using moderate caloric restriction in wintering mouse lemurs [17], the effects of resveratrol significantly differed from changes observed in caloric-restricted animals. In the mouse lemurs, caloric restriction led to an increase in the duration and depth of daily torpor bouts. These body temperature adjustments were efficient at preventing body-mass loss and were not associated with changes in gut hormones [17].

\section{Conclusion}

In conclusion, we demonstrated for the first time the short-term effects of resveratrol on the metabolism of an heterothermic primate. Resveratrol activates energy expenditure by inducing an increase in resting metabolic rate and a decrease in torpor patterns that play key roles in energy saving in this primate. Moreover, resveratrol had a satiety effect in this primate that reduced their spontaneous food intake. All of these changes participated in the limitation of pre-wintering fattening processes in which the increase in the glucose-dependent insulinotropic polypeptide levels would play an additive role. These results provide novel information on the potential effects of resveratrol on energy metabolism and control of body mass in a primate.

\section{Methods}

\section{Animals and animal care}

We used six male grey mouse lemurs (Microcebus murinus, Cheirogaleidae, primates) born in a laboratory breeding colony in Brunoy, France (Agreement \# 962773) from a population originally caught 40 years ago on the southwest coast of Madagascar. The animals were 3-yearold adults and presented a mean \pm standard error of the mean (SEM) body mass of $133 \pm 4 \mathrm{~g}$. Conditions were constant in respect to ambient temperature $\left(25^{\circ} \mathrm{C}\right)$, relative humidity (55\%), and ad libitum food availability. Behavioural and physiological seasonal changes in mouse lemurs are dependent on the photoperiod and are reproduced in captivity using an artificial photoperiodic regimen. In the breeding colony, animals were exposed to an artificial photoperiodic regimen consisting of alternating six-month periods of Malagasy winter-like short-day lengths (light:dark 10:14) and Malagasy summer-like long-day lengths (light:dark 14:10). Animals were studied during the five weeks following the shift from long to short day lengths corresponding to the pre-wintering fattening period. To minimize social influences, the animals 
were housed individually in cages $(0.4 \times 0.4 \times 0.6 \mathrm{~m})$ provided with nesting materials, and were separated from each other by wooden partitions. Each week and just before the daily food allotment, animals were weighed inside their nest box, to avoid any stress, using a balance accurate to $1 \mathrm{~g}$.

All animals were fed ad libitum during one week, with fresh fruit (bananas and apples) and a mixture of cereals, milk and eggs, providing them with a total of $126 \mathrm{~kJ}$ per day. The cereals were composed of $60 \%$ carbohydrates, $10 \%$ proteins and $30 \%$ lipids. The cereals were primarily wheat flour (96\%). The mixture was introduced $1 \mathrm{~h}$ before the beginning of the animal's nocturnal active phase (Figure $3 \mathrm{~A}$ ). Water was always given ad libitum. During the following four weeks (RSV1, RSV2, RSV3 and RSV4), the animals were fed the same as above but $200 \mathrm{mg} / \mathrm{kg}$ of RSV (Sequoia Research Products, United Kingdom) per day was added to the mixture. Prior to the study, we monitored the food intake of the six animals presented with a choice between a bowl of control food and a bowl of food supplemented with $200 \mathrm{mg} / \mathrm{kg} /$ day of RSV. Food was provided ad libitum in both bowls. Food intake was assessed by weighing the daily leftovers and correcting for water evaporation (calculated previously with the control mixture under the same environmental conditions). The average daily amounts of food eaten were similar between control and RSV supplemented groups $(t=1.738, d f=5$, $\mathrm{p}=0.143$ ), evidencing no significant difference in the palatability of the mixtures. To determine the exact quantity of food ingested by the animals, daily leftovers were

A)

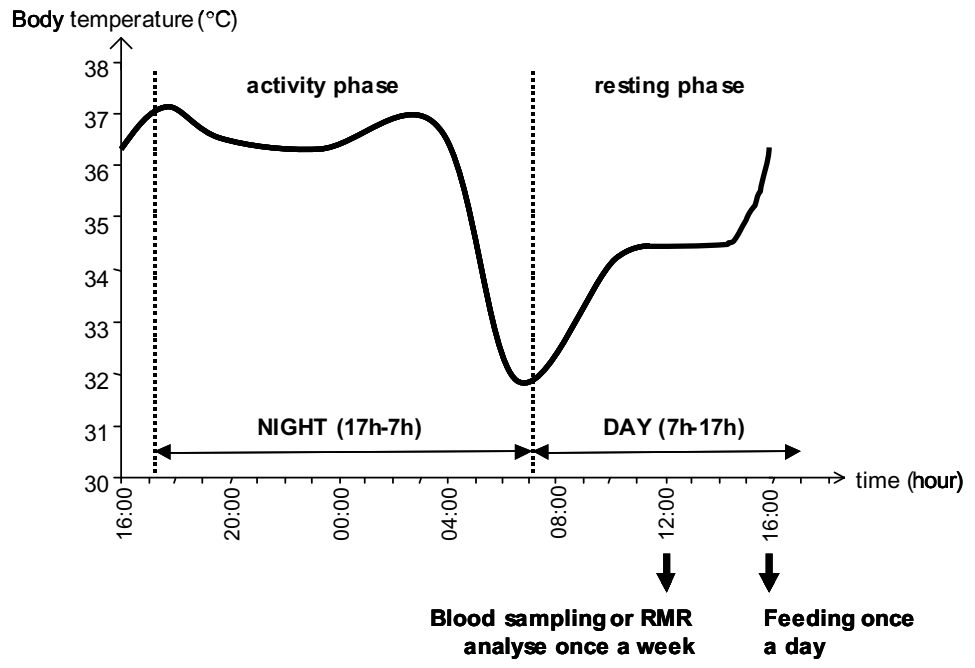

B)

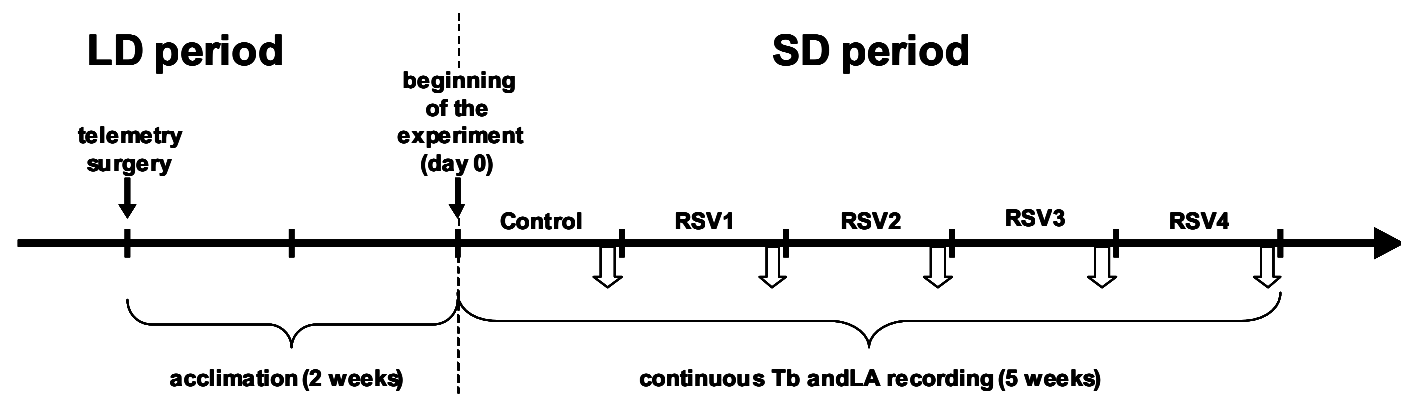

Figure 3 Experimental timetable. A) The activity phase (17h-7h) and the resting phase (7h-17h) are represented in this schematic profile of body temperature variations of one animal during one day. The animals were followed for five weeks: one control week and four weeks with RSV supplementation (200 mg/kg/day). The mouse lemurs were fed daily one hour before the beginning of their active phase during the five-week study. Blood sampling and measurement of the resting metabolic rate (RMR) were carried out once a week (each one on a different day) during the control period and each week of RSV treatment during their daily resting period, 4-6 $\mathrm{h}$ after the beginning of the light period to minimize the influence of circadian variations. B) This long-term experimental time line shows when the telemetry surgery, acclimation and first experiments were performed. The telemetry surgery was performed two weeks before the beginning of the short day period to allow animals to recover before beginning the experiment. The white arrows represent the moment when blood sampling, measurement of resting metabolic rate (RMR) and body weight were undertaken (once a week). The body temperature (Tb) and locomotor activity (LA) were continuously recorded during the five weeks from the shift to short day period. 
weighed and corrected for water evaporation as with the palatability control. All the procedures were carried out in accordance with the European Communities Council Directive (86/609/EEC). All the experiments were done under personal licence to experiment on mouse lemurs, delivered by the Ministry of Education and Science after approval of a local Ethics Committee ( $\mathrm{n}^{\circ} 91-305$, issued 20 July, 2006).

\section{Resting metabolic rate}

Oxygen consumption was measured in a closed indirect calorimetry system. Measurements on post-absorptive animals were made daily during their resting period, 4-6 $\mathrm{h}$ after the beginning of the light period to minimize the influence of circadian variations (Figure 3A). The animals were trained to nest in $2.5 \mathrm{l}$ opaque respiratory chambers with a woven floor to absorb any urine. The respiratory chamber was placed in a cabinet at a controlled ambient temperature of $25.0 \pm 0.5^{\circ} \mathrm{C}$, a value within the thermoneutral zone defined for the mouse lemur [38]. After a 20 min habituation phase with a constant air flow (2 l/ min) drawn through the respirometry chamber from bottom to top, the chamber was closed for a 40-min period. The air was dried prior to analysis using a silica gel. The $\mathrm{VO}_{2}$ consumed by the animal was calculated from initial and final concentrations of $\mathrm{O}_{2}$ in the chamber which were measured from dried gas using a SERVOMEX 570A paramagnetic gas analyser (Servomex Ltd., England) (accuracy $0.01 \% \mathrm{O}_{2}$ ). Calculations were made in Standard Temperature and Pressure, Dry and, the daily atmospheric humidity was accounted for. The oxygen analyser was routinely calibrated with $\mathrm{N}_{2}$ and atmospheric air assuming $21.00 \% \mathrm{O}_{2}$ as recommended by the manufacturer. Oxygen consumption was expressed as $\mathrm{ml} \mathrm{O}_{2} / \mathrm{h}$. The animals were weighed before each measurement. Oxygen consumption was corrected for the body weight of the animal [39]. Body temperature was not measured before the experiment to avoid disturbing sleeping animals but males never enter deep torpor at an ambient temperature of $25^{\circ} \mathrm{C}$ [40]. However, $\mathrm{O}_{2}$ consumption at $25^{\circ} \mathrm{C}$ cannot be defined as basal because the body temperature varies in the grey mouse lemur, thus values were referred to as resting metabolic rate (RMR) [15]. The values are given as mean \pm SEM.

\section{Recording of locomotor activity and body temperature}

The grey mouse lemur is a nocturnal species exhibiting high levels of locomotor activity (LA) during the dark period and complete rest during the light period. Under exposure to short days, the daily rhythm of body temperature $(\mathrm{Tb})$ in the mouse lemur is characterized by high $\mathrm{Tb}$ values during the active period and, before the onset of the light phase, a rapid and linear drop in $\mathrm{Tb}$ reaching minimal values after 3-4 hours. This hypothermia bout is followed by a spontaneous re-warming to normothermic $\mathrm{Tb}$ levels until the following dark phase (Figure 3A).

The recording of LA and Tb was obtained by telemetry at a constant ambient temperature of $25^{\circ} \mathrm{C}$. A small telemetric transmitter weighing 2.5 g (model TA10TA-F20, DataScience Co. Ltd, Minnesota, USA) was implanted into the visceral cavity under ketamine anaesthesia (Imalgene, $100 \mathrm{mg} / \mathrm{kg}$ ip, Merial, France). Telemetry surgeries were performed 15 days before the beginning of the short day period. After surgery, the animals were returned to their home cage and allowed to recover for 15 days before starting the experiment and the continuous recording of $\mathrm{Tb}$ from the beginning of the short day period. Total recovery was checked by visual inspection to ensure complete healing of the surgical incision and by verification of a stable daily pattern of $\mathrm{Tb}$ variations. Recording began in the first week following the shift to the short photoperiod (Figure $3 \mathrm{~B}$ ). A receiver board was positioned in the cage and LA (expressed in arbitrary units, a.u.) was continuously recorded during this interval by two antennas located in the receiver board which detected vertical and horizontal movements (X-Y coordinate system, Dataquest Lab Pro v. 3.0, Data Science Co. Ltd, Minnesota, USA). The $\mathrm{Tb}\left(\mathrm{in}^{\circ} \mathrm{C}\right)$ of the animals was recorded every $10 \mathrm{~min}$. The following parameters were analysed: daily amount of LA, mean $\mathrm{Tb}$ during the active nocturnal phase ( $\mathrm{Tb}$ night), mean $\mathrm{Tb}$ during the resting diurnal phase ( $\mathrm{Tb}$ day) and the minimal $\mathrm{Tb}$ value ( $\mathrm{Tb} \mathrm{min}$ ).

\section{Hormonal assays}

Blood sampling was carried out once a week during the control period and in each week of RSV treatment 4-6 h after the beginning of the light period to minimize the influence of circadian variations (Figure 3A). The blood samples were taken via the saphenous vein, without anaesthesia, before food allotment. The volume of blood sampled was $100 \mu \mathrm{l}$ and that represented less than $2 \%$ of the total blood volume of the animals. The blood samples were centrifuged at $7000 \mathrm{rpm}$ at $4^{\circ} \mathrm{C}$ for $30 \mathrm{~min}$. The plasma was stored at $-20^{\circ} \mathrm{C}$ according to the assay procedure. Levels of glucagon-like peptide 1 (GPL-1), pancreatic polypeptide (PP), peptide YY (PYY) and glucosedependent insulinotropic polypeptide (GIP) were measured in duplicate using the human gut hormones multiplex panel (LincoplexTM Multiplex Assays, Bioscience) and Luminex technology at the Saint Antoine Hospital in Paris dedicated to micro-assays in small animals (IRSSA, INSERM, IFR65, France), as previously described [17]. The average recoveries of known quantities of standard peptides (taken at the low, medium and high concentrations given in the assay) added to mouse lemur plasma were $89 \%$ for GIP, $83 \%$ for GLP1, $88 \%$ for PP and $107 \%$ for PYY. Inter-assay and intra-assay coefficients of variation were $<19 \%$ and $<11 \%$, respectively. 


\section{Statistics}

All values are expressed as mean \pm SEM. We used the Friedman test to assess significant variations in all of the studied parameters. Comparisons were considered to differ significantly when $\mathrm{p}<0.05$. Possible correlations between the energy balance parameters and gut hormone levels were assessed by Spearman's correlation test. All statistical computations were performed using SYSTAT for Windows (V9, SPSS Inc., Illinois, USA).

\section{Abbreviations}

a.u.: arbitrary unit; GIP: glucose-dependent insulinotropic polypeptide; GLP-1: glucagon-like peptide 1; LA: locomotor activity; PP: pancreatic polypeptide; PYY: peptide YY; RMR: resting metabolic rate; RSV: resveratrol; RSV1: first week of RSV supplementation; RSV2: second week of RSV supplementation; RSV3: third week of RSV supplementation; RSV4: fourth week of RSV supplementation; SEM: standard error of the mean; SIRT1: Silent mating type Information Regulation 2 homologue Type 1; Tb: body temperature; Tb night: mean Tb during the active nocturnal phase; Tb day: mean Tb during the resting diurnal phase; Tb min: minimal Tb value.

\section{Authors' contributions}

AD performed the experimental protocol, analysed the data and drafted the manuscript. SB participated in the design of the study and drafted the manuscript. FA conceived the study, participated in its design and coordination, performed the statistical analyses and drafted the manuscript. All authors read and approved the final manuscript.

\section{Acknowledgements}

Recognition is due to Dr Martine Perret for help in proofreading and improving the manuscript. Simon Miner is warmly thanked for reading the manuscript. We would like to thank Saint Antoine laboratory (IRSSA, Inserm IFR65, Paris, France) for gut hormone assays. This work was carried out with the financial support of The French National Research Agency (ANR) under the Programme National de Recherche en Alimentation et Nutrition Humaine (project ANR-06PNRA-010-01).

\section{Author Details}

${ }^{1}$ Mécanismes Adaptatifs et Evolution, UMR 7179 Centre National de la Recherche Scientifique, Muséum National d'Histoire Naturelle, Paris, France and 2Institut Pluridisciplinaire Hubert Curien, UMR 7178 CNRS Université de Strasbourg, Strasbourg, France

Received: 21 December 2009 Accepted: 22 June 2010

Published: 22 June 2010

\section{References}

1. Delmas D, Lancon A, Colin D, Jannin B, Latruffe N: Resveratrol as a Chemopreventive Agent: A Promising Molecule for Fighting Cancer. Curr Drug Targets 2006, 7:423-442.

2. Bavaresco L: Role of viticultural factors on stilbene concentrations of grapes and wine. Drugs Exp Clin Res 2003, 29:181-7.

3. Baur JA, Sinclair DA: Therapeutic potential of resveratrol: the in vivo evidence. Nat Rev Drug Discov 2006, 5(6):493-506.

4. Baur JA: Resveratrol, Sirtuins, and the Promise of a DR Mimetic. Mech Ageing Dev 2010, 131(4):261-269.

5. Picard F, Kurtev M, Chung N, Topark-Ngarm A, Senawong T, Machado de Oliveira R, Leid M, McBurney MW, Guarente L: Sirt1 promotes fat mobilization in white adipocytes by repressing PPAR-[gamma]. Nature 2004, 429(6993):771-776.

6. Sadruddin S, Arora R: Resveratrol: biologic and therapeutic implications. J Cardiometab Synd 2009, 4(2):102-6.

7. Ramadori G, Gautron L, Fujikawa T, Vianna CR, Elmquist JK, Coppari R: Central administration of resveratrol improves diet-induced diabetes. Endocrinology 2009, 150(12):5326-33.

8. Rivera L, Morón R, Zarzuelo A, Galisteo M: Long-term resveratrol administration reduces metabolic disturbances and lowers blood pressure in obese Zucker rats. Biochem Pharmacol 2009, 77(6):1053-63.
9. Cottart CH, Nivet-Antoine V, Laguillier-Morizot C, Beaudeux JL: Resveratrol bioavailability and toxicity in humans. Mol Nutr Food Res 2010, 54:1-10.

10. Swindell WR: Comparative analysis of microarray data identifies common responses to caloric restriction among mouse tissues. Mech Ageing Dev 2008, 129(3):138-53.

11. Feige JN, Lagouge M, Canto C, Strehle A, Houten S, Milne JC, Lambert PD, Mataki C, Elliott PJ, Auwerx J: Specific SIRT1 activation mimics low energy levels and protects against diet-induced metabolic disorders by enhancing fat oxidation. Cell Metab 2008, 8:347-358.

12. Lagouge M, Argmann C, Gerhart-Hines Z, Meziane H, Lerin C, Daussin F, Messadeq N, Milne J, Lambert P, Elliott P, Geny B, Laakso M, Puigserver P, Auwerx J: Resveratrol Improves mitochondrial function and protects against metabolic disease by activating SIRT1 and PGC-1 [alpha]. Cell 2006, 127(6):1109-1122.

13. Mayers JR, lliff BW, Swoap SJ: Resveratrol treatment in mice does not elicit the bradycardia and hypothermia associated with calorie restriction. FASEB Journal 2009, 23:1032-1040.

14. Baur JA, Pearson KJ, Price NL, Jamieson HA, Lerin C, Kalra A, Prabhu VV, Allard JS, Lopez-Lluch G, Lewis K, Pistell PJ, Poosala S, Becker KG, Boss O, Gwinn D, Wang MY, Ramaswamy S, Fishbein KW, Spencer RG, Lakatta EG, Le Couteur D, Shaw RJ, Navas P, Puigserver P, Ingram DK, de Cabo R, Sinclair DA: Resveratrol improves health and survival of mice on a highcalorie diet. Nature 2006, 444(7117):337-342.

15. Génin F, Perret M: Photoperiod-induced changes in energy balance in gray mouse lemurs. Physiol Behav 2000, 71(3-4):315-321

16. Terrien J, Zizzari P, Epelbaum J, Perret M, Aujard F: Daily rhythms of core temperature and locomotor activity indicate different adaptive strategies to cold exposure in adult and aged mouse lemurs acclimated to a summer-like photoperiod. Chronobiol Internat 2009 , 26:1-16.

17. Giroud S, Perret M, Le Maho Y, Momken I, Gilbert C, Blanc S: Gut hormones in relation to body mass and torpor pattern changes during food restriction and re-feeding in the gray mouse lemur. J Comp Physiol B 2008, 179(1):99-111.

18. Murphy KG, Dhillo WS, Bloom SR: Gut peptides in the regulation of food intake and energy homeostasis. Endocr Rev 2006, 27(7):719-727.

19. Shousha S, Nakahara K, Nasu T, Sakamoto T, Murakami N: Effect of glucagon-like peptide- 1 and -2 on regulation of food intake, body temperature and locomotor activity in the japanese quail. Neurosci lett 2007, 415(2):102-107.

20. Kojima S, Ueno N, Asakawa A, Sagiyama K, Naruo T, Mizuno S, Inui A: A role for pancreatic polypeptide in feeding and body weight regulation. Peptides 2007, 28(2):459-463.

21. Almeida L, Vaz-da-Silva M, Falcão A, Soares E, Costa R, Loureiro Al, Fernandes-Lopes C, Rocha JF, Nunes T, Wright L, Soares-da-Silva P. Pharmacokinetic and safety profile of trans-resveratrol in a rising multiple-dose study in healthy volunteers. Mol Nutr Food Res 2009, 53:S7-S15.

22. Nunes T, Almeida L, Rocha JF, Falcão A, Fernandes-Lopes C, Loureiro Al Wright L, Vaz-da-Silva M, Soares-da-Silva P: Pharmacokinetics of transresveratrol following repeated administration in healthy elderly and young subjects. J Clin Pharmacol 2009, 49(12):1477-1482.

23. Juan ME, Maijó M, Planas JM: Quantification of trans-resveratrol and its metabolites in rat plasma and tissues by HPLC. J Pharmaceut Biomed 2010, 51(2):391-398

24. Dausmann KH, Glos J, Ganzhorn JU, Heldmaier G: Hibernation in the tropics: lessons from a primate. J Comp Physiol B 2005, 175(3):147-155.

25. Dausmann K, Glos J, Heldmaier G: Energetics of tropical hibernation. $J$ Comp Physiol B 2009, 179(3):345-357.

26. Pearson KJ, Baur JA, Lewis KN, Peshkin L, Price NL, Labinskyy N, Swindell WR, Kamara D, Minor RK, Perez E, Jamieson HA, Zhang Y, Dunn SR, Sharma K, Pleshko N, Woollett LA, Csiszar A, Ikeno Y, Le Couteur D, Elliott PJ, Becker KG, Navas $P$, Ingram DK, Wolf NS, Ungvari Z, Sinclair DA, de Cabo R: Resveratrol delays age-related deterioration and mimics transcriptional aspects of dietary restriction without extending life span. Cell Metab 2008, 8:157-168.

27. Smith JJ, Keeney RD, Gagne D, Frushour B, Ladd W, Galonek H, Israelian K, Song J, Razvadauskaite G, Lynch A, Carney D, Johnson R, Lavu S, Iffland A, Elliott P, Lambert P, Elliston K, Jirousek M, Milne J, Boss O: Small molecules activators of SIRT1 replicate signaling pathways triggered by calorie restriction in vivo. BMC Syst Biol 2009, 3:31. 
28. Milne JC, Lambert PD, Schenk S, Carney DP, Smith JJ, Gagne DJ, Jin L, Boss O, Perni RB, Vu CB, Bemis JE, Xie R, Disch JS, Ng PY, Nunes JJ, Lynch AV, Yang H, Galonek H, Israelian K, Choy W, Iffland A, Lavu S, Medvedik O, Sinclair DA, Olefsky JM, Jirousek MR, Elliott PJ, Westphal CH: Small molecule activators of SIRT1 as therapeutics for the treatment of type 2 diabetes. Nature 2007, 450:712-716.

29. Field BC, Chaudhri OB, Bloom SR: Obesity treatment: novel peripheral targets. Brit J Clin Pharmaco 2009, 68(6):830-843.

30. Tome D, Schwarz J, Darcel N, Fromentin G: Protein, amino acids, vagus nerve signaling, and the brain. Am J Clin Nutr 2009, 90(3):838S-843S.

31. Turton MD, O'Shea D, Gunn I, Beak SA, Edwards CMB, Meeran K, Choi SJ, Taylor GM, Heath MM, Lambert PD, Wilding JPH, Smith DM, Ghatei MA, Herbert J, Bloom SR: A role for glucagon-like peptide-1 in the central regulation of feeding. Nature 1996, 379(6560):69-72.

32. Flint A, Raben A, Rehfeld JF, Holst JJ, Astrup A: The effect of glucagon-like peptide-1 on energy expenditure and substrate metabolism in humans. Int J obesity 2000, 24(3):288-298.

33. Meier JJ, Gallwitz B, Schmidt WE, Nauck MA: Glucagon-like peptide 1 as a regulator of food intake and body weight: therapeutic perspectives. Eur J Pharmacol 2002, 440(2-3):269-279.

34. Adams SH, Lei C, Jodka CM, Nikoulina SE, Hoyt JA, Gedulin B, Mack CM, Kendall ES: PYY[3-36] administration decreases the respiratory quotient and reduces adiposity in diet-induced obese mice. J Nutr 2006, 136(1):195-201.

35. Ding KH, Qing Z, Ding X, Chen HX, Della-Fera MA, Bollag RJ, Bollag WB, Gujral R, Baolin K, Sridhar S, Baile C, Curl W, Isales CM: Effects of glucosedependent insulinotropic peptide on behavior. Peptides 2006 27(11):2750-2755.

36. Yip RGC, Wolfe MM: GIP biology and fat metabolism. Life Sci 1999 66(2):91-103.

37. Roark AM, Bjorndal KA: Metabolic rate depression is induced by caloric restriction and correlates with rate of development and lifespan in a parthenogenetic insect. Exp Gerontol 2009, 44(6-7):413-419.

38. Aujard F, Perret M, Vannier G: Thermoregulatory responses to variations of photoperiod and ambient temperature in the lesser mouse lemur: a primitive or an advanced adaptive character? J Comp Physiol B 1998, 168:540-548.

39. Blanc S, Schoeller D, Kemnitz J, Weindruch R, Colman R, Newton W, Wink K, Baum S, Ramsey J: Energy expenditure of rhesus monkeys subjected to 11 years of dietary restriction. J Clin Endocr Metab 2003, 88(1):16-23.

40. Perret M, Aujard F, Vannier G: Influence of daylength on metabolic rate and daily water loss in the male prosimian primate Microcebus murinus. Comp Biochem Phys A 1998, 119(4):981-989.

doi: $10.1186 / 1472-6793-10-11$

Cite this article as: Dal-Pan et al., Resveratrol suppresses body mass gain in a seasonal non-human primate model of obesity BMC Physiology 2010, 10:11

Submit your next manuscript to BioMed Central and take full advantage of:

- Convenient online submission

- Thorough peer review

- No space constraints or color figure charges

- Immediate publication on acceptance

- Inclusion in PubMed, CAS, Scopus and Google Scholar

- Research which is freely available for redistribution

Submit your manuscript at www.biomedcentral.com/submit
C Biomed Central 